\title{
92. NUEVA LOCALIDAD DE PSILOTUM NUDUM (L.) PB.
}

\author{
Antonio J. DELGADO VÁZQUEZ y Luis F. SÁNCHEZ TUNDIDOR
}

New location of Psilotum nudum (L.) PB.

Palabras clave. Psilotum nudum, Psilotaceae, Cádiz, España

Key words. Psilotum nudum, Psilotaceae, Cádiz, Spain

Se han localizado dos nuevas poblaciones de Psilotum nudum (L.) PB. (Salvo, E., 1990) (7-XII-2002) en la provincia de Cádiz, en el término municipal de Jimena de la Frontera, dentro de los límites del Parque Natural de los Alcornocales, en el paraje conocido como Arroyo del Salado.

De la zona ya se conocía otra población del taxón (grupo disperso de individuos) (Galán De Mera, A. et al.,1996). La primera población, según se asciende por el arroyo, consta de un solo individuo de unos $35 \mathrm{~cm}$ con varios pies, y al cual se le han observado esporangios en diversas ocasiones. A unos 500 metros de distancia encontramos la otra población, que consta de 2 individuos bien diferenciados, de tamaño reducido (unos $15 \mathrm{~cm}$ ), y que surgen de una grieta en una roca justo en el centro del arroyo, donde el sol les da directamente.

El entorno donde se desarrollan estas nuevas poblaciones se puede considerar un "canuto", cauce bajo, encajado, siempre húmedo, típico de estas sierras, con una vegetación muy característica, de bosque de galería formado por Alnus glutinosa, principalmente, apareciendo también otros taxones como Nerium oleander, Quercus canariensis, Laurus nobilis, Hedera helix y Osmunda regalis. Junto a Psilotum nudum se encuentra Asplenium billotii, ambas incluibles en la clase fitosociológica Asplenietea rupestris (Pérez Latorre et al., 1999).

Las poblaciones de Andalucía se separan como Psilotum nudum var. molesworthae Iranzo, Prada y Salvo (Cabezudo, B. \& Salvo, E., 1987), atendiendo al menor tamaño y mayor grosor de los tallos. Sin embargo, se podría considerar esta diferenciación como una forma ecológica diferente, pues en regiones tropicales este taxón tiene una ecología distinta, llegando a ser incluso epífito, aprovechando la mayor humedad y temperatura del entorno; mientras que en nuestras latitudes se muestra como un elemento rupícola, ocupando grietas de rocas, grietas húmedas de arenisca con un reducido protosuelo, siempre con un marcado carácter heliófilo (Cabezudo, B. et al., 1999).

Se debe resaltar que en Europa, la distribución de este pteridófito, se reduce al Parque Natural de los Alcornocales, de aquí la importancia de su conservación (Cabezudo, et al., 1999).

Este taxón está considerado como raro, clasificado como En peligro de extinción para Andalucía (D. 104/94) y a nivel nacional (R.D. 439/90); y como Vulnerable a nivel internacional por la UICN. (Cabezudo, B. et al., 1999).

\section{BIBLIOGRAFÍA}

CABEZUDO, B., D. NAVAS, F. SÁNCHEZ y A. E. SALVO -1999- Psilotum nudum (L.)PB. In Blanca, G. et al. (Eds.), Libro Rojo de la Flora Silvestre Amenazada de Andalucía, T.1: 224 - 
227. Sevilla : Junta de Andalucía.

CABEZUDO, B. y A. E. SALVO -1987- Psilotum nudum (L.) Beauv. In Valdés, B., Talavera, S., \& Fernández-Galiano, E. (Eds.), Flora Vascular de Andalucía Occidental, Vol. I: 43. Barcelona: Ketres Editora.

GALÁN DE MERA, A., J. A. VICENTE ORELLANA, J. L. GONZÁLEZ y J. C. FERNÁNDEZ LUNA 1996- New Population of Psilotum nudum in SW Europe. Fern Gaz. 15 (3): 109-112.

PÉREZ LATORRE, A. V., A. GALÁN DE MERA, P. NAVAS, D. NAVAS, Y. GIL y B. CABEZUDO
-1999- Datos sobre la flora y vegetación del Parque Natural de los Alcornocales. Acta Bot. Malacitana 24: 133-184. Málaga.

SALVO, E. -1990- Guía de helechos de la península Ibérica y Baleares. Madrid. Pirámide.

Aceptado para su publicación en febrero de 2003

Dirección de los autores A. J. Delgado Vázquez: C/ Sol 43, San Pablo de Buceite, Cádiz.

\section{DOS TAXONES NATURALIZADOS EN LA PENÍNSULA IBÉRICA PRESENTES EN ANDALUCÍA OCCIDENTAL}

Abelardo APARICIO

Two naturalised taxa in the Iberian Peninsula present in west Andalusia.

Plabras clave. Hibiscus, Solanum, Andalucía.

Key words. Hibiscus, Solanum, Andalusia.

Se citan a continuación dos taxones naturalizados en la flora de la Península Ibérica que se han encontrado en la provincia de Sevilla, donde, según los datos disponibles, no habían sido citados. Los pliegos testigo se encuentran depositados en el herbario de la Universidad de Sevilla (SEV).

\section{Hibiscus trionum L.}

Originaria de América se encuentra actualmente diseminada por el sur de Europa, África, Asia y Australia. En España se encuentra esparcida por algunas provincias del este asociada a lugares húmedos en arrozales y otros regadíos. La hemos localizado en la provincia de Sevilla creciendo abundantemente en lugares húmedos cerca de acequias entre cultivos de algodón.

SEVILLA: Dos Hermanas, proximidades del río Guadaira. Cultivos de algodón y maíz.
UTM 30S 234068-4132393. 1.09.2003, A. Aparicio, F. García Martín \& A. Sousa.

\section{Solanum elaeagnifolium Cav.}

Planta americana, actualmente distribuida por gran parte del mundo, que en la Península Ibérica se localiza por el este español. La hemos encontrado como especie viaria en dos localidades en la provincia de Sevilla.

SEVILLA: Dos Hermanas, proximidades del río Guadaira. UTM 234282-4132388. 1.09.2003; Bormujos, UTM 29S 757234 4138682, 15.11.2003, J. Aparicio \& A. Aparicio.

Aceptado para su publicación en octubre de 2003

Dirección del autor. Departamento de Biología Vegetal y Ecología. Facultad de Farmacia. Universidad de Sevilla. 